\title{
Product and Kinetic Analysis of Oligomerization by Addition-Fragmentation Chain Transfer using Methyl $\alpha$-Bromomethylacrylate
}

\author{
Kenta TANAKA and Bunichiro YAMADA ${ }^{\dagger}$ \\ Department of Applied Chemistry, School of Engineering, Osaka City University, Osaka 558-8585, Japan
}

(Received March 20, 2002; Accepted July 8, 2002)

\begin{abstract}
Radical additions of 2-cyano-2-propyl radicals to styrene (St), methyl methacrylate (MMA), and ethyl acrylate (EA) in the presence of large amounts of addition fragmentation chain transfer (AFCT) agent, methyl $\alpha$ bromomethylacrylate (MBMA), gave low molecular weight unsaturated oligomers. The methylene protons of the $\omega$ unsaturated end groups can be distinguished by ${ }^{1} \mathrm{H}$ NMR spectroscopy depending on the number and the structure of the monomer units bound to the end groups. The relative amounts of oligomers containing one, two or three monomer units and the unsaturated end group were determined to evaluate the rate constants for chain transfer relative to propagation of the oligomer radicals. The rate constants for chain transfer were greater than those for propagation and the ratio of these rate constants depended on the chain length of the oligomer radical. MBMA gave its dimer together with the oligomers of St, MMA, and EA. These results confirm that propagating radicals smoothly add to MBMA to yield the adduct radical exclusively undergoing $\beta$-fragmentation and that homopropagation of MBMA is much slower than those of the monomers to function as an effective AFCT agent.

KEY WORDS Radical Polymerization / Elementary Reaction / Propagation / Chain Transfer / Addition-Fragmentation / Oligomer / End Group /
\end{abstract}

Addition-fragmentation chain transfer (AFCT) is indispensable for efficient synthesis of polymer bearing unsaturated end groups and control of the degree of polymerization because of advantages arising from its applicability to a variety of monomers and from chain transfer constants $\left(C_{\mathrm{tr}}\right)$ sometimes close to unity. ${ }^{1-9} \mathrm{Al}-$ though the unsaturated end group resulting from AFCT is not homopolymerizable, the end group is feasible to addition of a propagating radical followed by coupling with another propagating radical or fragmentation depending on the substituent of the double bond, the penultimate unit, and the attacking radical. ${ }^{10-13}$ Therefore, AFCT can also be utilized for polymer architecture such as preparation of branched and block copolymer simultaneously with control of molecular weight using bifunctional chain transfer agents. ${ }^{11,12}$

Methyl $\alpha$-bromomethylacrylate (MBMA) 2, 5, 6, 13, 14 as well as $\alpha$-(alkylthiomethyl)acrylate ${ }^{1-4}$ and $\alpha$ (arylsulfonylmethyl)acrylate ${ }^{7}$ are effective AFCT agents in the polymerizations of methyl methacrylate (MMA), styrene (St) and methyl acrylate (MA). In the cases of methyl $\alpha$-chloromethylacrylate ${ }^{15}$ and methyl $\alpha$-(2-carbomethoxyethyl)acrylate (MA dimer), ${ }^{16}$ the respective adduct radicals undergo propagation and fragmentation, simultaneously. Differences in behavior among the $\alpha$-(substituted methyl)acrylates may be explained by competitive reaction of $\alpha$-(substituted methyl)acryloyl radicals between fragmentation and propagation; the strength of the dissociating bond and steric hindrance to propagation may be decisive factors that govern the effectiveness as a chain transfer agent. An additional requirement on the chain transfer agent is rapid reinitiation by the expelled radical. The rates of reinitiation by bromine atom from MBMA and the subsequent few propagation steps seem to be slower than propagation of macroradicals, because the polymerization rates of conjugative monomers were slightly depressed in the presence of MBMA. ${ }^{5,14}$ Although the adduct radical of the $\alpha$-(arylsulfonylmethyl)acrylate and polymer radical was detected by ESR spectroscopy, ${ }^{7}$ detection of the adduct radical of MBMA was unsuccessful. ${ }^{17}$ The primary and secondary propagating radicals may exhibit different reactivities from sufficiently long propagating radicals toward monomer, because $\beta$-bromomethyland the 2-bromopropyl groups as the $\beta$-substituents of the respective radical centers are expected to result in different addition rates toward MBMA.

Under conventional conditions of radical polymerization, the oligomer radicals propagate rapidly and no oligomeric product can be isolated. Nitroxide trapping, which can compete with propagation, has been employed to estimate the reaction rates of oligomer radicals, and the propagating rate constants for primary propagating radicals $\left(k_{\mathrm{p} 1}\right)$ and secondary propagating radicals $\left(k_{\mathrm{p} 2}\right)$ have been separately obtained. ${ }^{18,19}$ Some monomers ${ }^{20-22}$ showed that the rate constants for the first few steps of propagation including the reaction of

${ }^{\dagger}$ To whom correspondence should be addressed (E-mail: yamada@a-chem.eng.osaka-cu.ac.jp). 
the primary and secondary propagating radicals are not the same as for macroradicals.

In this paper, the oligomers of MMA, St, and ethyl acrylate (EA) (M) were synthesized using large amounts of MBMA. The mixtures of oligomers obtained were analyzed by NMR spectroscopy to determine the composition of the product for consideration of competition of propagation with AFCT of the primary and secondary propagating radicals which can be shown by $\mathrm{Br}-\mathrm{M} \bullet$ and $\mathrm{Br}-\mathrm{M}_{2} \bullet$, respectively.

\section{EXPERIMENTAL}

\section{Materials}

MBMA was prepared as described in the literature. ${ }^{5}$ Commercially available St, MMA, and EA were distilled under reduced pressure before use. 2,2'Azobis(isobutyronitrile) (AIBN) was purified by recrystallization from methanol.

\section{Reaction Procedure}

A benzene solution of $5.0 \mathrm{~mol} \mathrm{~L}^{-1}$ of monomer, a variable amount of MBMA, and $5.0 \mathrm{mmol} \mathrm{L}^{-1}$ of AIBN in a glass ampoule was degassed, sealed under vacuum and immersed in a thermostated bath at $60^{\circ} \mathrm{C}$ for $0.5-$ $2.0 \mathrm{~h}$. After the reaction, the ampoules were immersed in an ice-water bath to prevent the further reaction. The solvent and the monomer and some amount of unreacted MBMA were evaporated from the resulted reaction mixture at room temperature.

\section{Measurements}

A recycle preparative high-performance liquid chromatograph (HPLC), Japan Analytical Industry LC-908 equipped with JAI GEL-2H and JAI GEL-1H columns and a differential refractometer detector, was employed for isolation of individual oligomers from the reaction mixtures for structural analysis by NMR using a JEOL JNM A-400 spectrometer. ${ }^{1} \mathrm{H}$ NMR (400 MHz) and ${ }^{13} \mathrm{C}$ NMR spectra $(100 \mathrm{MHz})$ of the oligomers dissolved in $\mathrm{CDCl}_{3}$ were recorded. 2D ${ }^{1} \mathrm{H},{ }^{1} \mathrm{H}-\mathrm{COSY}$ $(400 \mathrm{MHz})$ spectra were recorded using the standard pulse sequence on the same spectrometer in $\mathrm{CDCl}_{3}$ at room temperature. Based on the ${ }^{1} \mathrm{H}$ NMR spectra of chemical shift range from 5.0-6.5 ppm assigned to the unsaturated methylene protons, the molar ratios of reaction products bearing the unsaturated end group were obtained.

\section{RESULTS AND DISCUSSION}

\section{Conversion}

All the oligomers were preliminary separated from higher molecular weight products by HPLC, and the monomer conversion was not obtained. In the case of St, MMA, and MA, reduced polymerization rates in the presence of MBMA ([MBMA]/[M] $\leq 0.1)$ have been reported. ${ }^{5,14}$ The conversions of monomer as well as MBMA in the presence of a large amount of MBMA in the present study would thus be low enough to avoid further reaction of the resultant oligomer.

\section{St Oligomers}

AFCT in competition with propagation (Scheme 1) would be the dominant chain stopping event in the St polymerization because of a sufficiently high concentration of MBMA and a large chain transfer constant: $C_{\mathrm{t}}=2.34,60^{\circ} \mathrm{C}^{5}$ Figure 1a shows the HPLC elution curve of the reaction product in the presence of a comparable amount of MBMA to St, and the ${ }^{1} \mathrm{H}$ NMR spectrum of the main fraction is depicted in Figure 2. Two sets of signals with similar intensity at 5.42 and $6.11 \mathrm{ppm}$, and 5.83 and $6.33 \mathrm{ppm}$ indicate the presence of only two types of unsaturated oligomers. No resonances assignable to the olefinic protons of MBMA to be observed at 5.97 and $6.34 \mathrm{ppm}$ were detected. ${ }^{5}$

As shown in Figure 2, the intensity of the resonances due to the 2,6- and 3,5-protons of the phenyl group (7.15-7.20 and 7.28-7.35 ppm, respectively) ${ }^{23}$ in $\mathrm{Br}-$ $\mathrm{St}-\mathbf{a}$ is roughly twice that of the resonances due to the $\mathrm{C}_{2}=\mathrm{C}\left(\mathrm{CO}_{2} \mathrm{Me}\right)-$ of $\mathbf{a}(5.42$ and $6.11 \mathrm{ppm})$ where a denotes the unsaturated end group arising from AFCT. This figure also contains the COSY spectrum of the product mixture showing the correlations of the res-

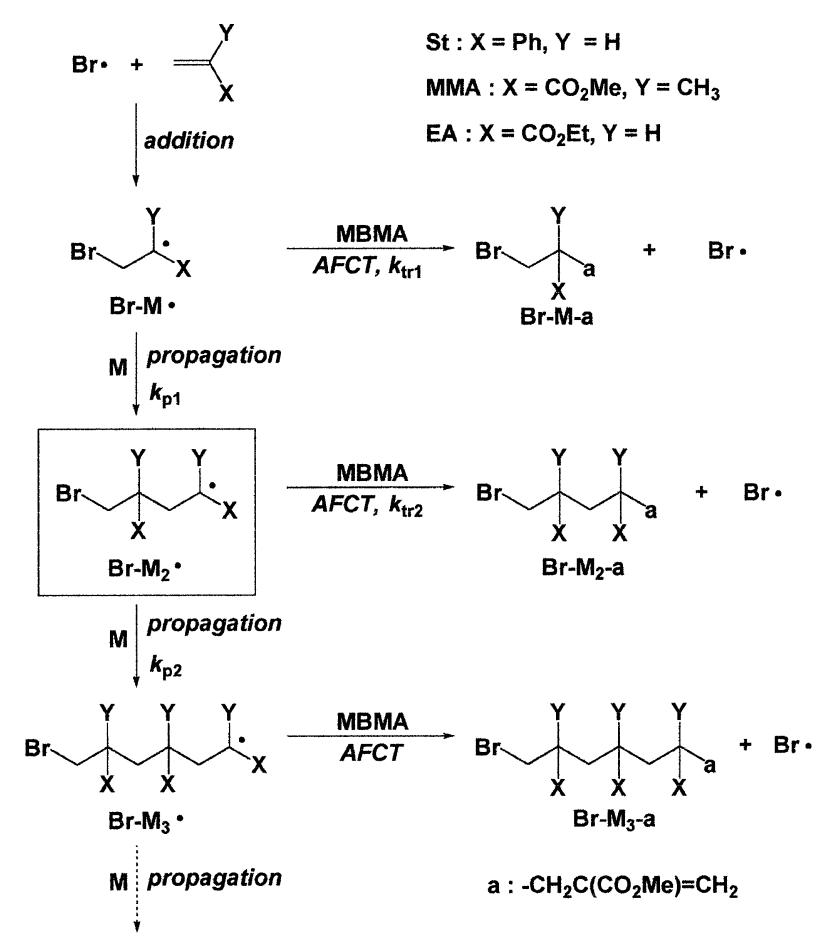

Scheme 1. 


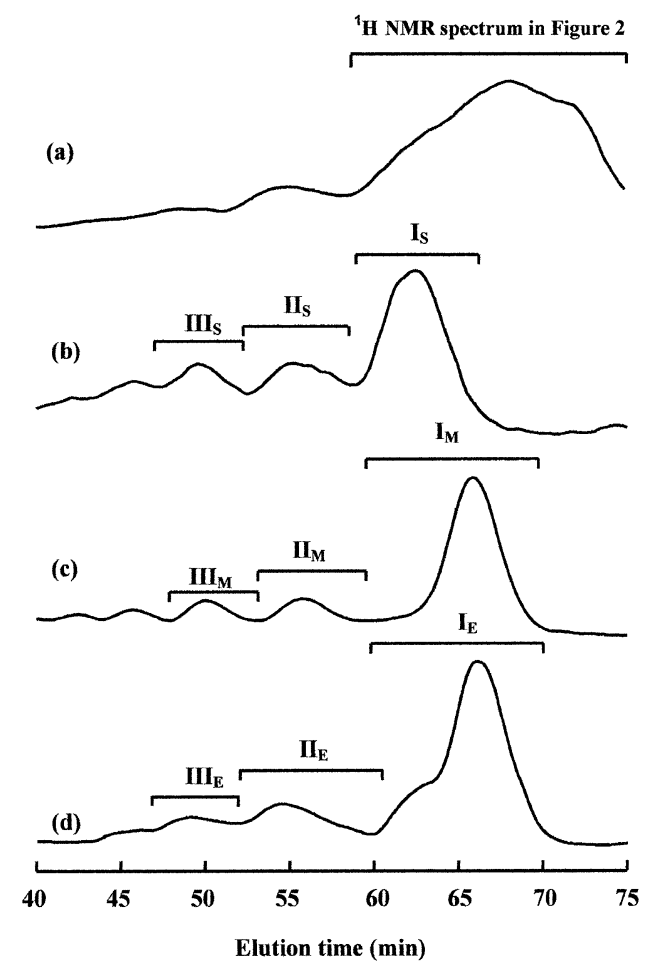

Figure 1. Recycled (once) HPLC elution curves of the products mixture initiated by AIBN $\left(5.0 \mathrm{mmol} \mathrm{L}^{-1}\right)$ in benzene at $60^{\circ} \mathrm{C}$ : (a), $[\mathrm{St}]=5.0 \mathrm{~mol} \mathrm{~L}{ }^{-1},[\mathrm{MBMA}]=2.8 \mathrm{~mol} \mathrm{~L}^{-1}, 30 \mathrm{~min}$; (b), [St] $=$ $5.0 \mathrm{~mol} \mathrm{~L}-1,[\mathrm{MBMA}]=0.1 \mathrm{~mol} \mathrm{~L}^{-1}, 40 \mathrm{~min}$; (c), [MMA] $=5.0$ mol L ${ }^{-1},[\mathrm{MBMA}]=1.4 \mathrm{~mol} \mathrm{~L}{ }^{-1}, 2 \mathrm{~h}$; (d), $[\mathrm{EA}]=5.0 \mathrm{~mol} \mathrm{~L}^{-1}$, $[\mathrm{MBMA}]=2.8 \mathrm{~mol} \mathrm{~L}^{-1}, 2 \mathrm{~h}$.

onance at $5.42 \mathrm{ppm}$ with that at $6.11 \mathrm{ppm}$, and these are unambiguously assigned to the $\underline{\mathrm{CH}}_{2}=\mathrm{C}\left(\mathrm{CO}_{2} \mathrm{Me}\right)-$ of $\mathrm{Br}-\mathrm{St}-\mathbf{a}$. The signals at 5.42 and $6.11 \mathrm{ppm}$ have correlations with the signals at 2.67 and $2.94 \mathrm{ppm}$, which are assigned to the $\mathrm{C}=\mathrm{C}\left(\mathrm{CO}_{2} \mathrm{Me}\right) \mathrm{CH}_{2}-$. The resonance at $3.27 \mathrm{ppm}$ correlating with the $\mathrm{CH}_{2}=\mathrm{C}$ was due to the $\mathrm{CH}$ of the St unit in $\mathrm{Br}-\mathrm{St}-\mathbf{a}$. Furthermore, the correlations of the two signals at 3.59 and $3.61 \mathrm{ppm}$ indicate that they can be assigned to the protons of the $\mathrm{BrCH}_{2}$ of $\mathrm{Br}-\mathrm{St}-\mathbf{a}$. Reinitiation by bromine atom produces the primary propagating radical, $\mathrm{Br}-\mathrm{St} \bullet$, and further reaction with MBMA gives $\mathrm{Br}-\mathrm{St}-\mathbf{a}$. The chemical shifts of the protons of $\mathrm{Br}-\mathrm{St}-\mathbf{a}$ are shown in Figure 3 together with those of other St oligomers mentioned later.

Some of the resonances in Figure 2 could not be assigned to neither $\mathrm{Br}-\mathrm{St}-\mathbf{a}$ nor $\mathrm{Br}-\mathrm{St}_{2}-\mathbf{a}$; nevertheless, all the phenyl protons detected are due to $\mathrm{Br}-\mathrm{St}-\mathbf{a}$ as confirmed by the consistent chemical shift and intensity ratio of the resonances. The resonance at 5.83 ppm correlates with the signals at 2.77 and $6.33 \mathrm{ppm}$ indicating that these resonances can be assigned to protons within the same molecule. It was deduced that the dimer of MBMA was formed as shown in Scheme 2 where $\mathrm{X}=\mathrm{Br}$. The dimer was also obtained by the reaction of MBMA using AIBN $\left(5 \mathrm{mmol} \mathrm{L}^{-1}\right)$ in the absence of $\mathrm{St}$ for three days at $60^{\circ} \mathrm{C}$ after purification by HPLC. All

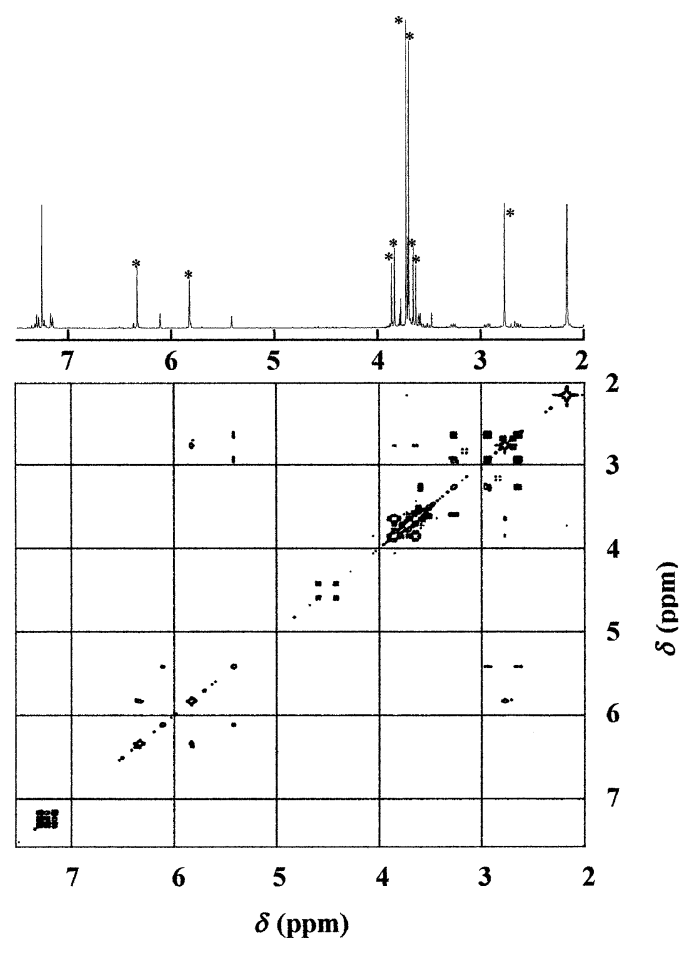

Figure 2. ${ }^{1} \mathrm{H}$ NMR and ${ }^{1} \mathrm{H},{ }^{1} \mathrm{H}-\mathrm{COSY}$ NMR spectra of the fraction signed in Figure 1a. The signals with the asterisks are due to the dimer of MBMA.

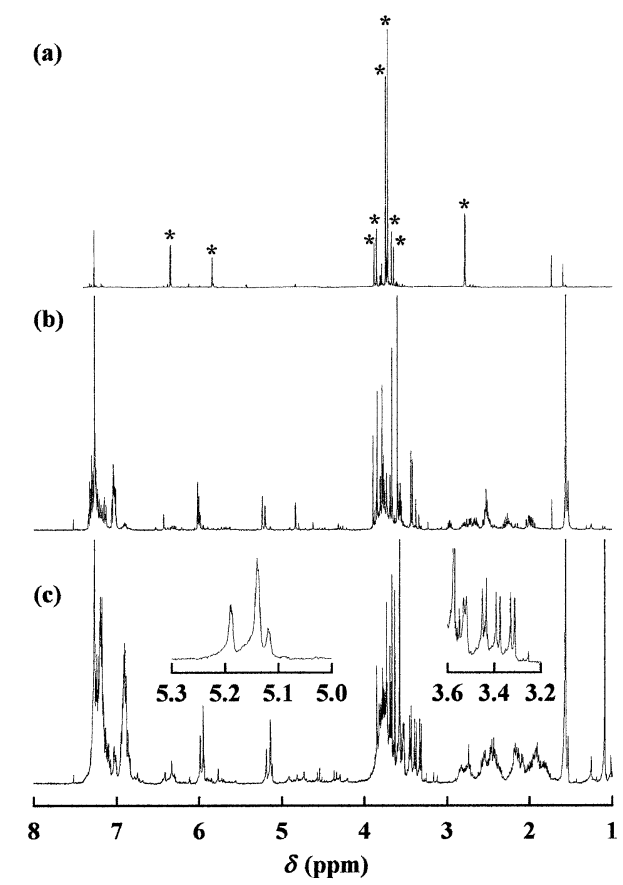

Figure 3. $\quad{ }^{1} \mathrm{H}$ NMR spectra of $\mathbf{I}_{\mathbf{S}}(\mathrm{a}), \mathbf{I I}_{\mathbf{S}}$ (b), and $\mathbf{I I I}_{\mathbf{S}}$ (c). The signals with the asterisks are due to the dimer of MBMA.

the signals of the NMR spectra of the dimer can be assigned as follows. ${ }^{1} \mathrm{H}$ NMR $\left(\mathrm{CDCl}_{3}\right): \delta=2.77(\mathrm{~s}, 2 \mathrm{H}$, $\left.\mathrm{CH}_{2} \mathrm{C}=\mathrm{C}\right), 3.71\left(\mathrm{~s}, 3 \mathrm{H}, \mathrm{CH}_{3}(\boldsymbol{d}\right.$ in Scheme 2)), 3.73 (s, $3 \mathrm{H}, \mathrm{OCH}_{3}$ (b in Scheme 2)), 3.65, $3.86\left(\mathrm{~d}, 2 \mathrm{H}, \mathrm{BrCH}_{2}\right)$, $5.83(\mathrm{~s}, 1 \mathrm{H}$, trans $-\mathrm{CH}=\mathrm{C})$, and $6.33(\mathrm{~s}, 1 \mathrm{H}$, cis $-\mathrm{CH}=\mathrm{C})$. ${ }^{13} \mathrm{C}$ NMR: $\delta=35.8\left(\mathrm{BrCH}_{2}\right), 36.0\left(\mathrm{CH}_{2} \mathrm{C}=\mathrm{C}\right), 51.2$ $\left(\mathrm{CCH}_{2}\right), 52.2\left(\mathrm{OCH}_{3}(\boldsymbol{d}\right.$ in Scheme 2$), 52.6\left(\mathrm{OCH}_{3}(\boldsymbol{b}\right.$ 


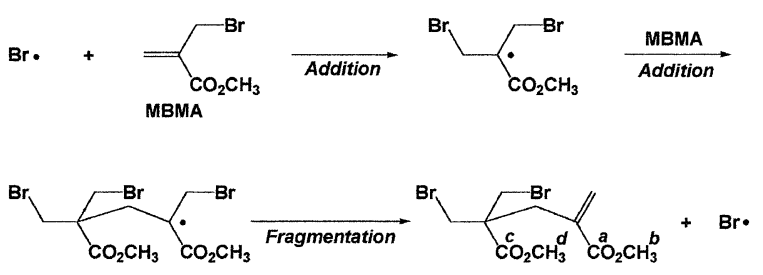

Scheme 2.

in Scheme 2)), $130.0\left(\mathrm{CH}_{2}=\mathrm{C}\right), 134.8\left(\mathrm{C}=\mathrm{CH}_{2}\right), 170.4$ $\left(\mathrm{CO}_{2} \mathrm{Me}(\boldsymbol{c}\right.$ in Scheme 2$\left.)\right)$, and $177.5\left(\mathrm{CO}_{2} \mathrm{Me}(\boldsymbol{a}\right.$ in Scheme 2)). A decrease in MBMA concentration resulted in the change in the HPLC elution curve from Figure 1a to Figure 1b. The ${ }^{1} \mathrm{H}$ NMR spectrum in Figure 3a, which is similar to the spectrum in Figure 2, shows formation of MBMA dimer as the main product in $\mathbf{I}_{\mathbf{s}}$ indicating that $\mathrm{Br} \bullet$ is feasible to add MBMA.

The addition of $\mathrm{Br}-\mathrm{St}$ - to MBMA results in $\mathrm{Br}-\mathrm{St}-$ $\mathbf{a}$, and the St radical would add to St leading to the secondary propagating radical, $\mathrm{Br}-\mathrm{St}_{2} \bullet$, which reacts with MBMA to give $\mathrm{Br}_{-} \mathrm{St}_{2}-\mathbf{a}$ under the conditions to form $\mathbf{I I}_{\mathbf{s}}$ and $\mathbf{I I I}_{\mathbf{s}}$. Figures $3 \mathrm{~b}$ and $3 \mathrm{c}$ illustrate the ${ }^{1} \mathrm{H}$ NMR spectra of $\mathbf{I I}_{\mathrm{s}}$, and $\mathbf{I I I}_{\mathrm{s}}$. The highly split signals at 3.3-3.6 ppm in Figures $3 \mathrm{~b}$ and $3 \mathrm{c}$ were assigned to the $\mathrm{BrCH}_{2}$ protons of $\mathrm{Br}-\mathrm{St}_{2}-\mathbf{a}$ and $\mathrm{Br}-\mathrm{St}_{3}-\mathbf{a}$ as well as the resonance at $c a .3 .6 \mathrm{ppm}$ for the $\mathrm{BrCH}_{2}$ protons of $\mathrm{Br}-\mathrm{St}-\mathbf{a}$. In Figure 3b, the resonances at 5.1-5.2 ppm suggest the presence of only two types of unsaturated oligomers; no additional resonances were assigned to the protons of the unsaturated methylene. $\mathrm{Br}_{-} \mathrm{St}_{2}-\mathbf{a}$ and $\mathrm{Br}-\mathrm{St}_{3}-\mathbf{a}$, which have two and four sets of enantiomers, respectively, can be distinguished. Therefore, it could be concluded from the longer elution time for $\mathbf{I I}_{\mathrm{S}}$ than $\mathbf{I I I _ { \mathrm { S } }}$ (Figure 1) that the resonances at 5.20 and $5.24 \mathrm{ppm}$, and four-line (two lines of four lines actually overlapping) resonance centered at $c a .5 .15 \mathrm{ppm}$ can be assigned to the trans $-\mathrm{CH}=\mathrm{C}\left(\mathrm{CO}_{2} \mathrm{Me}\right)-$ of $\mathrm{Br}-\mathrm{St}_{2}-\mathbf{a}$ and $\mathrm{Br}-\mathrm{St}_{3}-\mathbf{a}$, respectively, in contrast to $5.42 \mathrm{ppm}$ for the corresponding proton of $\mathrm{Br}-\mathrm{St}-\mathbf{a}$.

It was revealed by ${ }^{1} \mathrm{H}$ NMR spectroscopy that $\mathbf{I}_{\mathrm{S}}$ contains $\mathrm{Br}-\mathrm{St}-\mathbf{a}$ and the MBMA dimer and that $\mathbf{I}_{\mathbf{S}}$ and III $_{\mathrm{S}}$ consist of $\mathrm{Br}-\mathrm{St}_{2}-\mathbf{a}$ and $\mathrm{Br}-\mathrm{St}_{3}-\mathbf{a}$. The chemical shifts of the protons of $\mathrm{Br}-\mathrm{St}-\mathbf{a}, \mathrm{Br}-\mathrm{St}_{2}-\mathbf{a}$, and $\mathrm{Br}_{-} \mathrm{St}_{3}-$ a are summarized in Figure 4. Although the monomer and dimer radicals of MBMA might add to St followed by AFCT, expected products of these additions were not detected in the ${ }^{1} \mathrm{H}$ NMR spectra of $\mathbf{I}_{\mathbf{s}}$, $\mathbf{I I}_{\mathbf{s}}$, and $\mathbf{I I I} \mathbf{I}_{\mathbf{s}}$. After addition of the MBMA radical to monomer, the radical formed would extend the main chain to polymer radical in competition with AFCT. Only a small portion of the monomer reacted could be isolated as the oligomers, and the product from the MBMA radical among the oligomeric products of the monomer would be too small amount to be detected.
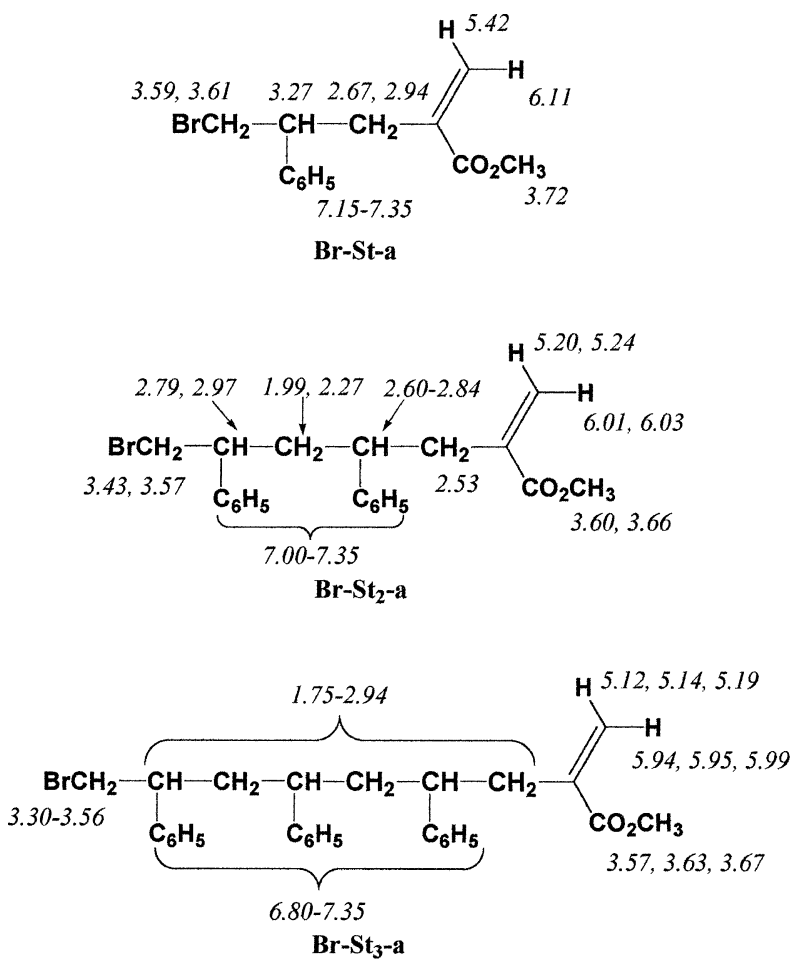

Figure 4. ${ }^{1} \mathrm{H}$ NMR chemical shifts of protons of the $\mathrm{St}$ oligomers in ppm. $\mathrm{Br}-\mathrm{St}_{2}-\mathbf{a}$ and $\mathrm{Br}_{-} \mathrm{St}_{3}-\mathbf{a}$ have the stereoisomers showing two or three different chemical shifts for the individual protons.

All the main peaks in the NMR spectra were assigned as in Figure 4 except for the resonances at 4.84, 5.98, and $6.43 \mathrm{ppm}$ (the intensity ratio of the resonances relative to the $\mathrm{C}_{2}=\mathrm{C}\left(\mathrm{CO}_{2} \mathrm{Me}\right)-$ of $\mathrm{Br}-\mathrm{St}-\mathbf{a}$ were 0.41 , 0.25 , and 0.23 , respectively) correlating with each other were observed in the spectrum of $\mathbf{I I}_{\mathbf{s}}$. Additionally, the ratio of the total intensity of the signal assigned to the phenyl protons $(6.6-7.4 \mathrm{ppm})$ to those assigned to methoxy and $\mathrm{Br}-\mathrm{CH}_{2}-$ protons $(3.2-4.0 \mathrm{ppm})$ is unexpectedly small as a compound consisting of two St units and one MBMA unit. However, the resonances cannot be due to neither $\mathrm{Br}-\mathrm{St}-\mathbf{a}$ nor the MBMA dimer, and the unknown resonances cannot be assigned to the $\mathrm{CH}_{2}=\mathrm{C}\left(\mathrm{CO}_{2} \mathrm{Me}\right)-$ of $\mathrm{Br}-\mathrm{St}-\mathrm{MBMA}-\mathbf{a}$ referring to the MBMA dimer. The unsaturated group of the unknown compound which could be formed by a reaction other than the sequence of addition to St followed by AFCT leading to the product without St unit.

\section{MMA Oligomers}

In conformity with $C_{\mathrm{t}}=0.93$ for MMA polymerization, ${ }^{5}$ the reaction mixture of MMA with MBMA initiated by AIBN yielded oligomeric products as shown in Scheme 1. The reaction products were examined by HPLC, and the elution curve is shown in Figure 1c. The ${ }^{1} \mathrm{H}$ NMR spectrum in Figure 5 shows that $\mathbf{I}_{\mathbf{M}}$ mainly consists of the MBMA dimer. Br-MMA-a could also be present in the fraction $\mathbf{I}_{\mathbf{M}}$ because the hydrodynamic 


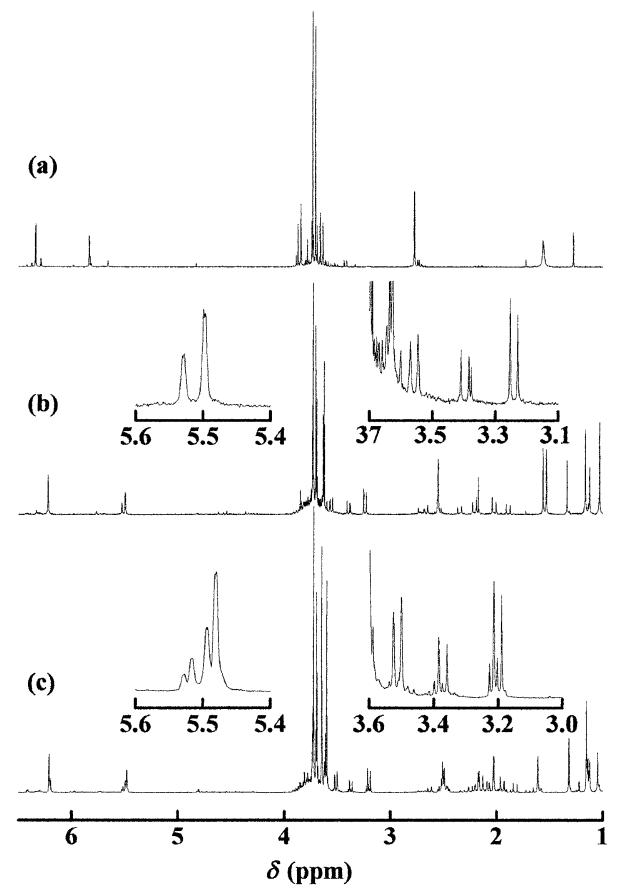

Figure 5. ${ }^{1} \mathrm{H}$ NMR spectra of $\mathbf{I}_{\mathbf{M}}(\mathrm{a}), \mathbf{I I}_{\mathbf{M}}(\mathrm{b})$, and $\mathbf{I I I}_{\mathbf{M}}$ (c). The signals with the asterisks are due to the dimer of MBMA.

volume of the MBMA dimer can be expected to be similar to that of Br-MMA-a. All the ${ }^{1} \mathrm{H}$ NMR chemical shifts for the protons of $\mathrm{Br}-\mathrm{MMA}-\mathbf{a}$ are summarized in Figure 6.

$\mathbf{I I}_{\mathbf{M}}$ and $\mathbf{I I I}_{\mathbf{M}}$ should comprise mainly $\mathrm{Br}-\mathrm{MMA}_{2}-$ a and $\mathrm{Br}-\mathrm{MMA}_{3}-\mathbf{a}$, respectively, as deduced from a shorter elution time than $\mathrm{Br}-\mathrm{MMA}-\mathbf{a}$. The ${ }^{1} \mathrm{H}$ NMR chemical shifts of some of the protons of $\mathrm{Br}-\mathrm{MMA}_{\mathrm{n}}-$ a are expected to depend on tacticity because $\mathrm{Br}-$ $\mathrm{MMA}_{2}-\mathbf{a}$ has two stereogenic centers. The spectrum of $\mathbf{I I}_{\mathbf{M}}$ in Figure $5 \mathrm{~b}$ shows the resonances of the cis- and trans $-\mathrm{CH}=\mathrm{C}\left(\mathrm{CO}_{2} \mathrm{Me}\right)-$ at 5.50 and 5.53 , and $6.22 \mathrm{ppm}$ for $\mathrm{Br}-\mathrm{MMA}_{2}-\mathbf{a}$ referring to the chemical shifts of the $\mathrm{C}_{2}=\mathrm{C}\left(\mathrm{CO}_{2} \mathrm{Me}\right)-$ of the PMMA obtained in the presence of MBMA. ${ }^{5}$ The eight lines at 1.8-2.4 ppm may be assigned to the $\mathrm{CH}_{2}$ protons between two asymmetric carbons of the consecutive MMA units. Furthermore, the six lines at 3.2-3.6 ppm in Figure 5b are a part of the resonances due to the $\mathrm{BrCH}_{2}-$ of $\mathrm{Br}-\mathrm{MMA}_{2}-\mathbf{a}$ because the chemical shift range is in reasonable agreement with the eight lines resonance at the corresponding methylene protons of the PMMA obtained in the presence of MBMA. ${ }^{5}$ The remaining two lines for the resonances due to the $\mathrm{BrCH}_{2}$ of $\mathrm{Br}-\mathrm{MMA}_{2}-\mathbf{a}$ were hidden by the resonances due to the $\mathrm{CH}_{3} \mathrm{O}$ of MMA unit. Other signals were assigned using systematic correlations appeared in the COSY spectrum referring to the spectrum of the PMMA ${ }^{5,25}$ as listed in Figure 6.

The spectrum of $\mathbf{I I I}_{\mathbf{M}}$ given in Figure $5 \mathrm{c}$ is comparable to the spectrum in Figure 5a which exhibits fewer lines at the respective chemical shift ranges. It was de-
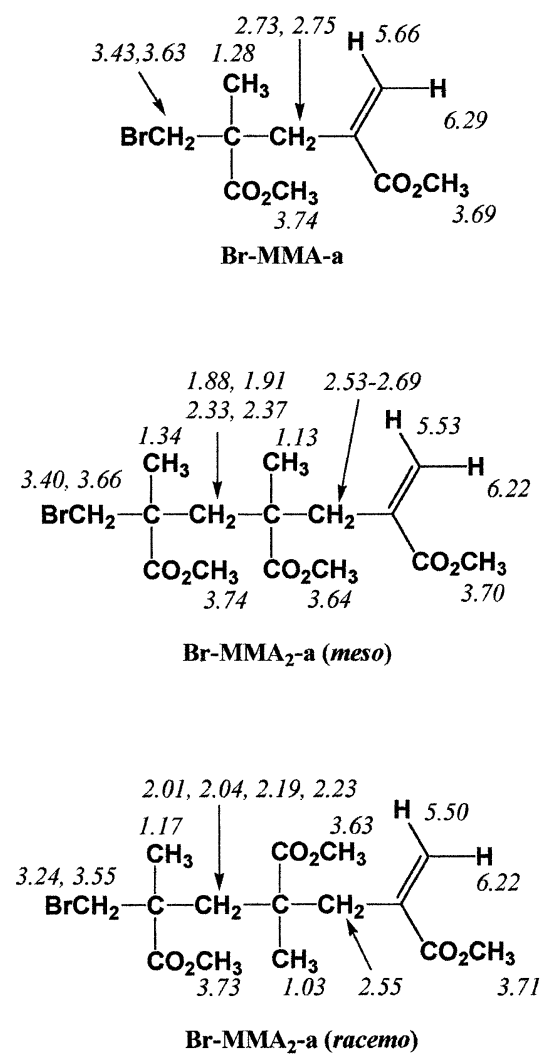

Figure 6. ${ }^{1} \mathrm{H}$ NMR chemical shifts of protons of obtained MMA oligomers in ppm.

duced that the main component of $\mathbf{I I I}_{\mathbf{M}}$ is $\mathrm{Br}-\mathrm{MMA}_{3}-\mathbf{a}$ with three stereogenic centers. The eight possible isomers predicted are listed in Figure 7. The ${ }^{1} \mathrm{H}$ NMR spectra of the enantiomers are identical, and the signal for each trans $-\mathrm{C} \underline{\mathrm{H}}=\mathrm{C}\left(\mathrm{CO}_{2} \mathrm{Me}\right)-$ appears at $5.48-$ $5.53 \mathrm{ppm}$. However, the chemical shifts of the resonance due to the $c i s-\underline{C} \underline{H}=\mathrm{C}\left(\mathrm{CO}_{2} \mathrm{Me}\right)-$ was $c a .6 .2 \mathrm{ppm}$ regardless of the structure of the oligomer. A total of eight lines at $c a .3 .2-3.4 \mathrm{ppm}$ can be assigned to the part of the spectrum of the $\mathrm{BrCH}_{2}$ of $\mathrm{Br}-\mathrm{MMA}_{3}-\mathbf{a}$ as well as that of $\mathrm{Br}-\mathrm{MMA}_{2}-\mathbf{a}$. The remaining lines are probably hidden by the stronger signals due to the $\mathrm{CH}_{3} \mathrm{O}$ at lower magnetic field. The intensity ratios of the four lines due to the trans- $\underline{\mathrm{H}}=\mathrm{C}\left(\mathrm{CO}_{2} \mathrm{Me}\right)-$ in Figure $5 \mathrm{c}$ at $5.48,5.49,5.52$, and $5.53 \mathrm{ppm}(1.0: 0.57: 0.29$ : 0.13 ) are in good agreement with those of the lines due to the $\mathrm{BrCH}_{2}$ at $3.19,3.36,3.21$, and $3.38 \mathrm{ppm}(1$ : $0.54: 0.30: 0.17)$. Coincidence of the intensity ratios would indicate that these protons are assigned to the respective enantiomers arising from combination of meso- and reacemo-diad configurations ${ }^{5,24}$ as summarized in Figure 7.

Figures $5 \mathrm{~b}$ and $5 \mathrm{c}$ show the resonances due to the unsaturated end groups of $\mathrm{Br}-\mathrm{MMA}_{2}-\mathbf{a}$ and $\mathrm{Br}-\mathrm{MMA}_{3}-$ a at $5.4-6.3 \mathrm{ppm}$, indicating that $\mathbf{I I}_{\mathbf{M}}$ and $\mathbf{I I I}_{\mathbf{M}}$ consist of $\mathrm{Br}-\mathrm{MMA}_{2}-\mathbf{a}$ and $\mathrm{Br}-\mathrm{St}_{3}-\mathbf{a}$, respectively. Actually, no other resonances assigned to the methylene pro- 

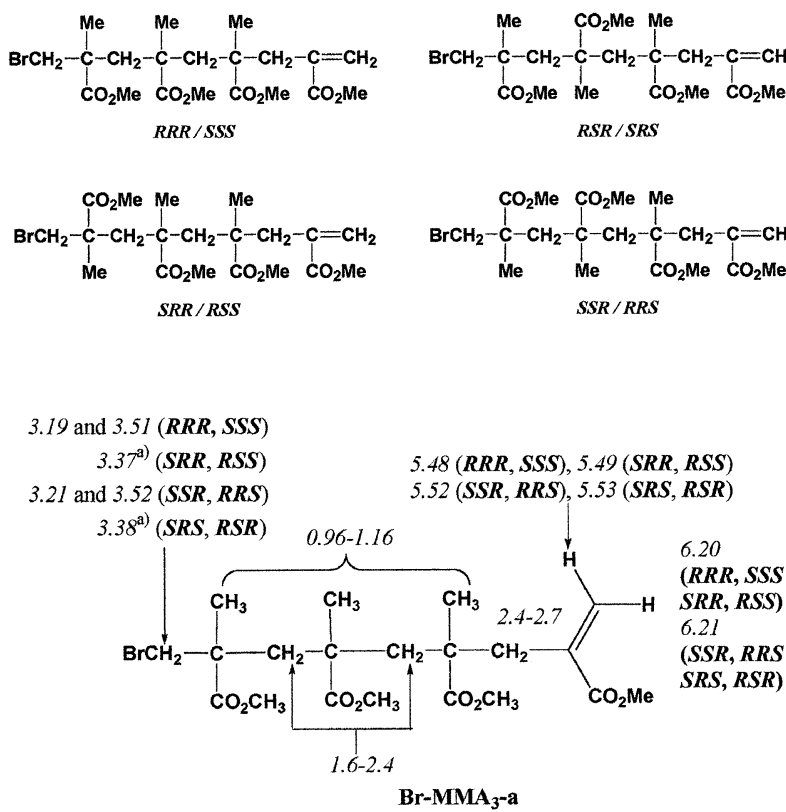

Figure 7. Four sets of enantiomers of $\mathrm{Br}-\mathrm{MMA}_{3}-\mathbf{a}$ shown by Fischer projections and the chemical shifts of their protons in ppm. a) Overlapping with the methoxy protons.

tons of other unsaturated end group were observed. It can be concluded that all the end groups detected are formed by the competitive reactions of the $\mathrm{Br}-\mathrm{MMA} \cdot$, $\mathrm{Br}-\mathrm{MMA}_{2} \bullet$, and $\mathrm{Br}-\mathrm{MMA}_{3} \bullet$ with MMA and MBMA according to Scheme 1.

\section{EA Oligomers}

EA as well as St and MMA yielded oligomers as shown in Scheme 1: $C_{\mathrm{tr}}=2.93$ for MA polymerizaton. ${ }^{5}$ The HPLC elution curve in Figure 1d was observed for the reaction mixture of EA. $\mathbf{I}_{\mathbf{E}}$ was a mixture of the MBMA dimer and Br-EA-a (ca. $2: 1)$ as confirmed by the ${ }^{1} \mathrm{H}$ NMR spectrum depicted in Figure $8 \mathrm{a}$. The intensity ratio of the signals due to the trans $-\mathrm{C} \underline{\mathrm{H}}=\mathrm{C}\left(\mathrm{CO}_{2} \mathrm{Me}\right)-$ at $5.70 \mathrm{ppm}$, the $\mathrm{CH}_{2} \mathrm{O}$ at $4.18 \mathrm{ppm}$, and the $\mathrm{CH}_{3}$ at $1.27 \mathrm{ppm}$ is $1.00: 1.97: 2.85$ which is close to $1: 2: 3$ predicted for Br-EA-a. The characteristic resonances of $\mathrm{Br}-\mathrm{EA}_{2}-\mathbf{a}$, the structure of which is shown in Figure 9, are found in the spectrum in Figure $8 \mathrm{~b}$ together with weak resonances due to the MBMA dimer. The ${ }^{1} \mathrm{H}$ NMR spectrum of $\mathbf{I I I}_{\mathbf{E}}$ is depicted in Figure 8c, and the resonance due to the $\mathrm{BrCH}_{2}-$ at $>3.4 \mathrm{ppm}$ is too complicated to be assigned in detail because of the coupling of the protons bound to the adjacent $\alpha$-carbon and the presence of two enantiomers. The COSY spectrum indicated that the correlation of the signals can be used for the unambiguous assignment summarized in Figure 9. The signals at 5.58 and $6.20 \mathrm{ppm}$ are assignable to the $\mathrm{CH}_{2}=\mathrm{C}\left(\mathrm{CO}_{2} \mathrm{Me}\right)-$ of $\mathrm{Br}-\mathrm{EA}_{2}-\mathbf{a}$. The intensity of the resonance due to the $\mathrm{CH}_{2} \mathrm{O}$ at $4.0-4.3 \mathrm{ppm}$ and those due to the $\mathrm{CH}_{3}$ at 1.1-

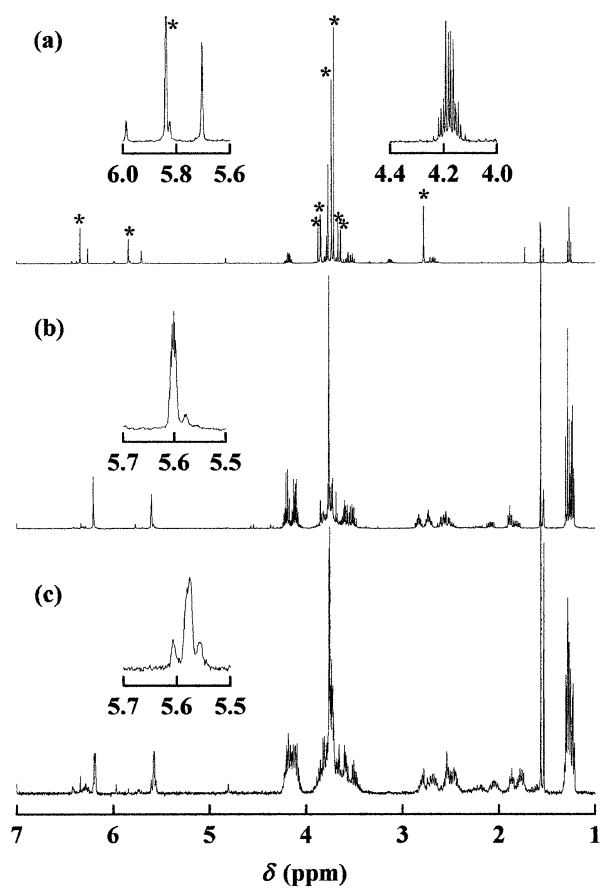

Figure 8. ${ }^{1} \mathrm{H}$ NMR chemical shifts of protons of $\mathbf{I}_{\mathbf{E}}(\mathrm{a}), \mathbf{I I}_{\mathbf{E}}(\mathrm{b})$, and $\mathbf{I I I}_{\mathbf{E}}$ (c) in ppm. The signals with the asterisks are due to the dimer of MBMA.
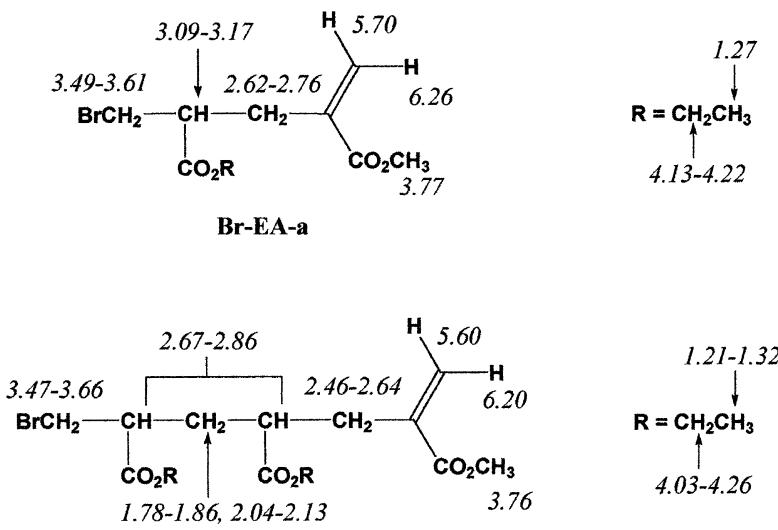

$\mathbf{B r}-\mathbf{E A}_{2}-\mathbf{a}$

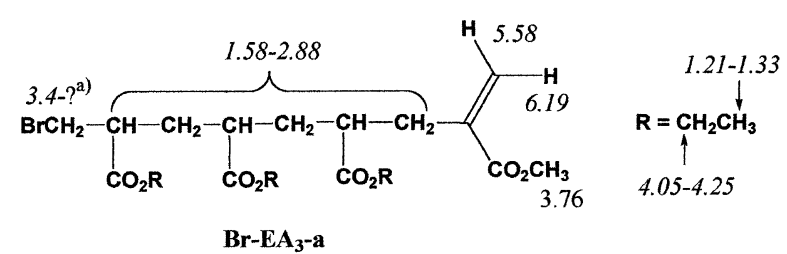

Figure 9. ${ }^{1} \mathrm{H}$ NMR chemical shifts of protons of EA oligomers

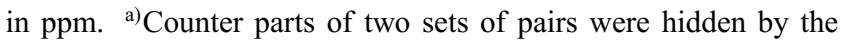
resonances due to $\mathrm{CH}_{3} \mathrm{O}$.

$1.4 \mathrm{ppm}$ are roughly twice and three times of that due to the $\mathrm{C} \underline{\mathrm{H}}=\mathrm{C}\left(\mathrm{CO}_{2} \mathrm{Me}\right)-$. Other signals were assigned using the COSY spectrum. The resonances of $\mathrm{Br}-\mathrm{EA}_{3}-\mathbf{a}$ were also assigned similarly as listed in Figure 9.

Formation of the significant amount of unsaturated end group other than those of the EA oligomers can be ruled out because the main resonances at 5.6-6.3 ppm 
are due to the EA oligomers consisting of up to three EA units. During the polymerization of acrylic esters, intra- and intermolecular hydrogen abstractions yielding mid-chain radical cannot be neglected in the polymerization of acrylate. ${ }^{25-32}$ However, mid-chain radical formation in competition with fast AFCT actually would not affect the structure and amount of the oligomers of EA up to only the degree of polymerization of three.

\section{Reactivities of Propagating Radicals}

If the oligomers are formed by the reactions given in Scheme 1, eqs $1-3$ can be derived.

$$
\begin{aligned}
& \frac{\mathrm{d}\left[\mathrm{Br}-\mathrm{M}_{2} \bullet\right.}{\mathrm{d} t}=k_{\mathrm{p} 1}[\mathrm{Br}-\mathrm{M} \bullet][\mathrm{M}]-k_{\mathrm{p} 2}\left[\mathrm{Br}-\mathrm{M}_{2} \bullet\right][\mathrm{M}] \\
& -k_{\mathrm{tr} 2}\left[\mathrm{Br}-\mathrm{M}_{2} \bullet\right][\mathrm{MBMA}] \\
& \frac{\mathrm{d}[\mathrm{Br}-\mathrm{M}-\mathbf{a}]}{\mathrm{d} t}=k_{\mathrm{tr} 1}[\mathrm{Br}-\mathrm{M} \bullet][\mathrm{MBMA}] \\
& \frac{\mathrm{d}\left[\mathrm{Br}-\mathrm{M}_{2}-\mathbf{a}\right]}{\mathrm{d} t}=k_{\mathrm{tr} 2}\left[\mathrm{Br}-\mathrm{M}_{2}\right][\mathrm{MBMA}]
\end{aligned}
$$

where the subscripts $\mathrm{p} 1, \mathrm{p} 2$, and $\mathrm{p}$ denote propagations of the primary, secondary, and ordinary propagating radical, respectively. The subscripts $\operatorname{tr} 1, \operatorname{tr} 2$, and tr are designated to chain transfer of the primary, secondary, and ordinary propagating radicals, respectively. For example, $k_{\mathrm{p} 1}$ means $k_{\mathrm{p}}$ for primary propagating radical.

At the steady state where all the concentrations of the transient species remain almost constant, the following equations can be obtained from eqs 2 and 3 ,

$$
\frac{\mathrm{d}[\mathrm{Br}-\mathrm{M}-\mathbf{a}]}{\mathrm{d}\left[\mathrm{Br}-\mathrm{M}_{2}-\mathbf{a}\right]}=\frac{k_{\mathrm{tr} 1}[\mathrm{Br}-\mathrm{M} \bullet]}{k_{\mathrm{tr} 2}\left[\mathrm{Br}-\mathrm{M}_{2} \bullet\right]}
$$

The ratio of $\mathrm{d}[\mathrm{Br}-\mathrm{M}-\mathbf{a}] / \mathrm{d}\left[\mathrm{Br}-\mathrm{M}_{2}-\mathbf{a}\right]$ can be calculated from ${ }^{1} \mathrm{H}$ NMR spectral intensities of the $\mathrm{CH}_{2}=\mathrm{C}\left(\mathrm{CO}_{2} \mathrm{Me}\right)-$ of the corresponding products as the products ratios, $[\mathrm{Br}-\mathrm{M}-\mathbf{a}] /\left[\mathrm{Br}-\mathrm{M}_{2}-\mathbf{a}\right]$, at low conversion.

$$
\frac{[\mathrm{Br}-\mathrm{M}-\mathbf{a}]}{\left[\mathrm{Br}-\mathrm{M}_{2}-\mathbf{a}\right]}=\frac{k_{\mathrm{tr} 1}[\mathrm{Br}-\mathrm{M} \bullet]}{k_{\mathrm{tr} 2}\left[\mathrm{Br}-\mathrm{M}_{2} \bullet\right.}
$$

Equation 1 may be converted to eq 6 since the left-hand side of eq 1 is equal to zero at the steady state with respect to $\mathrm{Br}-\mathrm{M}_{2} \bullet$.

$$
\frac{[\mathrm{Br}-\mathrm{M} \bullet]}{\left[\mathrm{Br}-\mathrm{M}_{2} \bullet\right]}=\frac{k_{\mathrm{p} 2}}{k_{\mathrm{p} 1}}+\frac{k_{\mathrm{tr} 1}}{k_{\mathrm{tr} 2}} \frac{[\mathrm{MBMA}]}{[\mathrm{M}]}
$$

Equation 5 can be written as follows by use of eq 6 .

$$
\frac{[\mathrm{Br}-\mathrm{M}-\mathbf{a}]}{\left[\mathrm{Br}-\mathrm{M}_{2}-\mathbf{a}\right]}=\frac{k_{\mathrm{tr} 1}}{k_{\mathrm{p} 1}} \frac{k_{\mathrm{p} 2}}{k_{\mathrm{tr} 2}}+\frac{k_{\mathrm{tr} 1}}{k_{\mathrm{p} 1}} \frac{[\mathrm{MBMA}]_{0}}{[\mathrm{M}]_{0}}
$$

Therefore, a plot of $[\mathrm{Br}-\mathrm{M}-\mathbf{a}] /\left[\mathrm{Br}-\mathrm{M}_{2}-\mathbf{a}\right]$ vs. $[\mathrm{MBMA}]_{0} /[\mathrm{M}]_{0}$ should give a linear relationship where $k_{\mathrm{tr} 1} / k_{\mathrm{p} 1}$ and $k_{\mathrm{tr} 2} / k_{\mathrm{p} 2}$ which correspond to the chain transfer constants for the primary and secondary propagating radical can be obtained from the slope and the intercept, respectively. It is noted that eq 1 involves the terms showing the rates of formation and consumption of $\mathrm{Br}-\mathrm{M} \cdot$. Formation of higher molecular weight products including polymer would not affect the validity of eq 1 because the second and third terms of eq 1 may be given by eqs 2 and 3 leading to eq 7 . The ratios of the rate constants, $k_{\mathrm{tr} 1} / k_{\mathrm{p} 1}$ and $k_{\mathrm{tr} 2} / k_{\mathrm{p} 2}$, can be evaluated based on the quantities experimentally determined, $[\mathrm{Br}-\mathrm{M}-\mathbf{a}] /\left[\mathrm{Br}-\mathrm{M}_{2}-\mathbf{a}\right]$, and formation of polymer, the MBMA dimer, and other products would not bias the product ratio.

The resonances of the trans $-\mathrm{CH}=\mathrm{C}\left(\mathrm{CO}_{2} \mathrm{Me}\right)-$ of $\mathrm{Br}-$ $\mathrm{St}-\mathbf{a}(5.42 \mathrm{ppm})$ and $\mathrm{Br}_{-} \mathrm{St}_{2}-\mathbf{a}(5.21$ and $5.24 \mathrm{ppm})$ were conveniently used to evaluate the product ratio. However, the signals due to the $\mathrm{CH}_{2}=\mathrm{C}\left(\mathrm{CO}_{2} \mathrm{Me}\right)-$ of $\mathrm{Br}-\mathrm{MMA}_{2}-\mathbf{a}(5.50,5.53$, and $6.22 \mathrm{ppm})$ overlap with those of $\mathrm{Br}-\mathrm{MMA}_{3}-\mathbf{a}(5.48-5.53,6.20$, and $6.21 \mathrm{ppm})$ and the resonances at 5.48 and $6.20 \mathrm{ppm}$ due to the unsaturated end group of PMMA-a. ${ }^{5}$ Therefore, $\mathbf{I I I}_{\mathbf{M}}$ and higher molecular weight products were separated from the bulk reaction mixture of MMA using HPLC before determination of [Br-MMA-a]/[Br-MMA $\left.{ }_{2}-\mathbf{a}\right]$. In the case of the reaction of EA, the intensities of the signals arising from the $c i s-\underline{\mathrm{H}}=\mathrm{C}\left(\mathrm{CO}_{2} \mathrm{Me}\right)-$ of $\mathrm{Br}-\mathrm{EA}-$ a at $6.26 \mathrm{ppm}$ was weaker than that at $5.70 \mathrm{ppm}$ by $c a$. $10 \%$ in intensity. The signal at $5.70 \mathrm{ppm}$ probably overlapped with some unknown signal. Consequently, the resonance at $6.26 \mathrm{ppm}$ (cis-) for $\mathrm{Br}-\mathrm{EA}-\mathbf{a}$ and $5.60 \mathrm{ppm}$ (trans-) for the $\mathrm{Br}-\mathrm{EA}_{2}-\mathbf{a}$ were chosen in the calculations. The expanded ${ }^{1} \mathrm{H}$ NMR spectra used for determination of $[\mathrm{Br}-\mathrm{M}-\mathbf{a}] /\left[\mathrm{Br}-\mathrm{M}_{2}-\mathbf{a}\right]$ for each monomer are depicted in Figure 10.

The plots of $[\mathrm{Br}-\mathrm{M}-\mathbf{a}] /\left[\mathrm{Br}-\mathrm{M}_{2}-\mathbf{a}\right]$ vs. $[\mathrm{MBMA}]_{0} /$ $[\mathrm{M}]_{0}$ according to eq 7 are shown in Figure 11, and linear relationships are obtained. For the plot of EA, $k_{\mathrm{tr} 1} / k_{\mathrm{p} 1}$ and $k_{\mathrm{tr} 2} / k_{\mathrm{p} 2}$ were calculated from the range of the slope and intercept as shown in Table I because the experimental points at the lowest $[\mathrm{MBMA}]_{0} /[\mathrm{M}]_{0}$ strongly affects the slope. The solid and broken lines are drawn with consideration of all the experimental points and the points except for the lower point at $[\mathrm{MBMA}]_{0} /[\mathrm{M}]_{0}=0.2$, respectively. The line drawn based on the points except for the high point gave infinitely large $k_{\mathrm{tr} 2} / k_{\mathrm{p} 2}$ which is an erroneous value. The $k_{\mathrm{tr} 1} / k_{\mathrm{p} 1}$ and $k_{\mathrm{tr} 2} / k_{\mathrm{p} 2}$ values which are larger than unity in Table I are not in agreement with those of $C_{\mathrm{tr}}\left(=k_{\mathrm{tr}} / k_{\mathrm{p}}\right)$ of MBMA for the respective polymerizations. The $k_{\mathrm{tr} 1} / k_{\mathrm{p} 1}$ and $k_{\mathrm{tr} 2} / k_{\mathrm{p} 2}$ values for St and EA are greater than those for MMA as well as $C_{\text {tr }}$ value suggesting that only a small effect of the end group on the reactivity ratios of the radicals because $C_{\text {tr }}$ cannot be affected by the end 


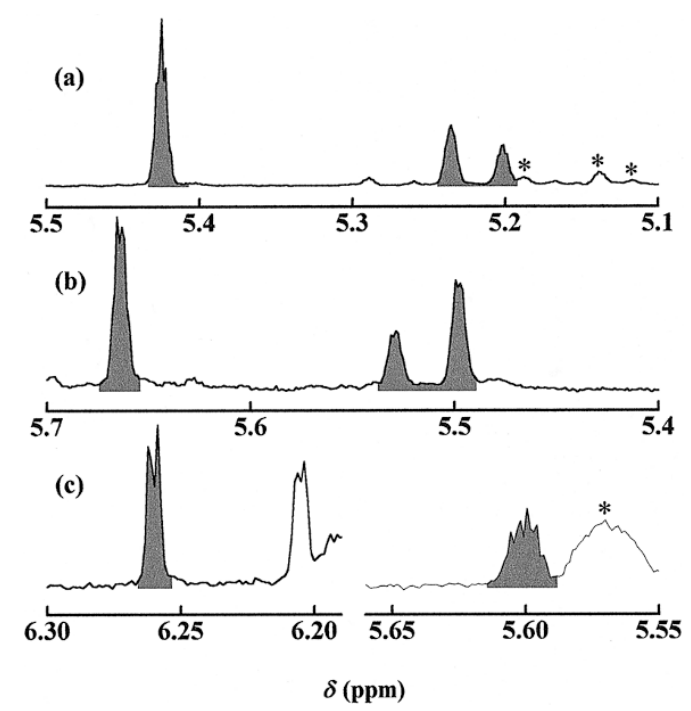

Figure 10. ${ }^{1} \mathrm{H}$ NMR spectra to obtain $[\mathrm{Br}-\mathrm{M}-\mathbf{a}] /\left[\mathrm{Br}-\mathrm{M}_{2}-\mathbf{a}\right]$ for St before separation by HPLC (a), MMA after the removal of $\mathrm{Br}-\mathrm{MMA}_{3}-\mathbf{a}$ and higher molecular weight products by HPLC (b), and EA before separation by HPLC (c). *indicates the signals of $\mathrm{CH}_{2}=\mathrm{C}\left(\mathrm{CO}_{2} \mathrm{Me}\right)-$ protons of $\mathrm{Br}-\mathrm{M}_{3}-\mathbf{a}$. Shadowed peaks were used for calculation of the amounts of $\mathrm{Br}-\mathrm{M}-\mathbf{a}$ (lower magnetic field) and $\mathrm{Br}-\mathrm{M}_{2}-\mathbf{a}$ (higher magnetic field).

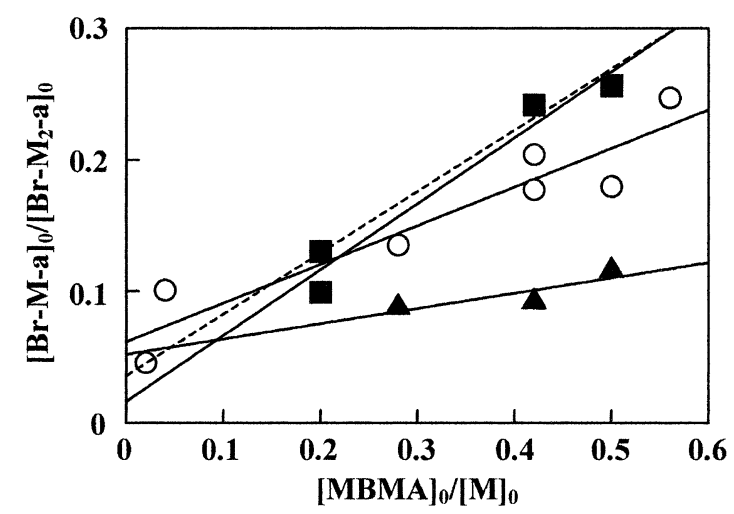

Figure 11. Plots of $[\mathrm{Br}-\mathrm{M}-\mathbf{a}] /\left[\mathrm{Br}-\mathrm{M}_{2}-\mathbf{a}\right]$ vs. $[\mathrm{MBMA}]_{0} /[\mathrm{M}]_{0}$ for oligomerizations of $\mathrm{St}(\bigcirc), \operatorname{MMA}(\boldsymbol{\Delta})$, and $\operatorname{EA}(\boldsymbol{\square})$ at $60^{\circ} \mathrm{C}$.

group. All $k_{\mathrm{tr} 1} / k_{\mathrm{p} 1}$ values are less than $k_{\mathrm{tr} 2} / k_{\mathrm{p} 2}$ values indicating that faster AFCT relative to propagation tends to occur at the second step of propagation than the first step.

One of the reasons for a large difference between $k_{\mathrm{tr} 1} / k_{\mathrm{p} 1}$ or $k_{\mathrm{tr} 2} / k_{\mathrm{p} 2}$, and $C_{\mathrm{tr}}$ for EA might be ascribed to the uncertainty in $k_{\mathrm{p}}$ value of acrylic ester. ${ }^{27,28} k_{\mathrm{p}}$ values for the monomers are also summarized in Table I, and the larger $k_{\mathrm{p}}$ for EA than St and MMA by two orders are noted. $C_{\text {tr }}$ for EA as the ratio of $k_{\mathrm{p}}$ to $k_{\mathrm{tr}}$ might be greater than 2.9 because the polymerization of acrylic ester in the absence of chain transfer agent is already affected by back biting followed by fragmentation to decrease chain length. ${ }^{31,32}$

For further consideration, the $k_{\mathrm{p} 1}$ and $k_{\mathrm{p} 2}$ values with respect to the primary and secondary propagating radi-
Table I. The ratio of the rate constants according to the plots in Figure 11, and $k_{\mathrm{p}}$ value and $C_{\mathrm{tr}}$ from the literatures

\begin{tabular}{ccccc}
\hline Monomer & $k_{\mathrm{tr} 1} / k_{\mathrm{p} 1}{ }^{\mathrm{a}}$ & $k_{\mathrm{tr} 2} / k_{\mathrm{p} 2}{ }^{\mathrm{b}}$ & $k_{\mathrm{p}}{ }^{\mathrm{c}}\left(\mathrm{L} \mathrm{mol}^{-1} \mathrm{~s}^{-1}\right)$ & $C_{\mathrm{tr}}{ }^{\mathrm{d}}$ \\
\hline St & 2.9 & 4.8 & 337 & 2.3 \\
MMA & 1.2 & 2.2 & 820 & 0.9 \\
EA & $4.0-4.7$ & $10-13$ & 30600 & $2.9^{\mathrm{e}}$ \\
\hline
\end{tabular}

${ }^{\mathrm{a}}$ The slope of the linear relationship in Figure 11. ${ }^{\mathrm{b}} \mathrm{Calculated}$ from the intercept on the ordinate of the plot in Figure 11. ${ }^{\mathrm{c}} k_{\mathrm{p}}$ for St and MMA at $60^{\circ} \mathrm{C}$ from refs 33 and 34, respectively. $k_{\mathrm{p}}$ for $n$-butyl acrylate at $60^{\circ} \mathrm{C}$ as $k_{\mathrm{p}}$ for EA from ref $35 .{ }^{\mathrm{d}} C_{\mathrm{tr}}$ for St and MMA from ref $5 .{ }^{\mathrm{e}} C_{\text {tr }}$ for MA from ref 5 .

cals at $60^{\circ} \mathrm{C}$ were required. The $k_{\mathrm{p} 1}$ and $k_{\mathrm{p} 2}$ for $\mathrm{R}-\mathrm{St}_{\mathrm{n}} \bullet$ ( $n=1$ or 2 ) where $\mathrm{R}$ was the fragment from AIBN or benzoin were assumed based on the results obtained by GPC analysis of polymer prepared by pulsed laser polymerization at $60^{\circ} \mathrm{C} .^{21}$ The $k_{\mathrm{p} 1}$ and $k_{\mathrm{p} 2}$ at $60^{\circ} \mathrm{C}$ for $\mathrm{H}-\mathrm{MMA}_{\mathrm{n}} \bullet$ and $\mathrm{PhCO}_{2}-\mathrm{MA}_{\mathrm{n}} \bullet(n=1$ or 2$)$ were determined by kinetic analysis of catalytic chain transfer ${ }^{22}$ and the nitroxide trapping method, ${ }^{18}$ respectively. The values of $k_{\mathrm{p} 1}, k_{\mathrm{p} 2}$, and $k_{\mathrm{p}}$, which are summarized in Table II, increase in the following order: St $<$ MMA $<$ EA. The fragment of initiator as the end group of the oligomers radical would affect the reactivities of the primary and the secondary propagating radicals. In such a case, the effect of the end group on $k_{\mathrm{p} 1}$ could be more significant than that on $k_{\mathrm{p} 2}$ to bias the common tendency, $k_{\mathrm{p} 1}>k_{\mathrm{p} 2}$, because different types of the groups, 2-cyano-2-propyl or $\mathrm{PhC}(\mathrm{OH}), \mathrm{H}$, and $\mathrm{PhCO}_{2}$, were bound to the respective monomer units as the end groups. The polar effect of the end group through $\mathrm{C}-\mathrm{C}$ bond cannot be the prominent reason for $k_{\mathrm{p} 1}>k_{\mathrm{p} 2}$. Alternatively, the steric effect was considered to be a dominant factor to decrease $k_{\mathrm{p} 2}$ from $k_{\mathrm{p} 1}$, and the minute effect of the end group might be predicted in conformity with the consideration based on $k_{\mathrm{tr} 1} / k_{\mathrm{p} 1}, k_{\mathrm{tr} 2} / k_{\mathrm{p} 2}, k_{\mathrm{tr}} / k_{\mathrm{p}}$, and $C_{\mathrm{tr}}$. It was considered that the $k_{\mathrm{p} 1}$ and $k_{\mathrm{p} 2}$ values for the oligomer radicals in the present study can be approximated by those for the respective radicals of St, MMA, and MA.

A significant difference in bulkiness, steric effect, between the one and two monomer units consisting of the oligomer radicals would cause the common tendency, $k_{\mathrm{p} 1}>k_{\mathrm{p} 2}$. Difference in the bulkiness between the one and two monomer units would be the largest for MMA unit because of an 1,1-disubstituted ethylenic structure of MMA unit; St and EA units are monosubstituted ethylenic structures. Comparison of $k_{\mathrm{p}}$ values for polymer radicals in Table I with those of $k_{\mathrm{p} 1}$ and $k_{\mathrm{p} 2}$ in Table II reveals $k_{\mathrm{p} 1}>k_{\mathrm{p} 2}>k_{\mathrm{p}}$ for the St and MMA polymerizations. However, $k_{\mathrm{p} 2}<k_{\mathrm{p}}$ for EA and the $k_{\mathrm{p}}$ might be overestimated. ${ }^{27,28}$ Using the experimentally evaluated $k_{\mathrm{tr} 1} / k_{\mathrm{p} 1}$ and $k_{\mathrm{tr} 2} / k_{\mathrm{p} 2}$, and $k_{\mathrm{p} 1}$ and $k_{\mathrm{p} 2}$ from the literatures, we calculated $k_{\mathrm{tr} 1}$ and $k_{\mathrm{tr} 2}$ values as in Ta- 
Table II. $k_{\mathrm{p}}$ Values for oligomer radicals at $60^{\circ} \mathrm{C}$ from the literatures, and numerical values calculated

\begin{tabular}{|c|c|c|c|c|c|c|c|}
\hline Monomer & $\frac{k_{\mathrm{p} 1}}{\mathrm{~L} \mathrm{~mol}^{-1} \mathrm{~s}^{-1}}$ & $\frac{k_{\mathrm{p} 2}}{\mathrm{~L} \mathrm{~mol}^{-1} \mathrm{~s}^{-1}}$ & $k_{\mathrm{p} 1} / k_{\mathrm{p} 2}$ & $\frac{k_{\mathrm{tr} 1}{ }^{\mathrm{a}}}{\mathrm{L} \mathrm{mol}^{-1} \mathrm{~s}^{-1}}$ & $\frac{k_{\mathrm{tr} 2}{ }^{\mathrm{b}}}{\mathrm{L} \mathrm{mol}^{-1} \mathrm{~s}^{-1}}$ & $k_{\mathrm{tr} 1} / k_{\mathrm{tr} 2}$ & $\frac{k_{\mathrm{tr}}{ }^{\mathrm{c}}}{\mathrm{L} \mathrm{mol}^{-1} \mathrm{~s}^{-1}}$ \\
\hline$\overline{\mathrm{St}}$ & $4000^{\mathrm{d}}$ & $900^{d}$ & 3.8 & 11600 & 4320 & 2.7 & 775 \\
\hline MMA & $14000^{\mathrm{e}}$ & $3600^{\mathrm{e}}$ & 12.4 & 16800 & 3240 & 5.2 & 738 \\
\hline EA & $37000^{f}$ & $14000^{\mathrm{f}}$ & 3.3 & $\begin{array}{l}148000- \\
173900\end{array}$ & $\begin{array}{l}140000- \\
182000\end{array}$ & $1.0-0.96$ & 88740 \\
\hline
\end{tabular}

Table III. Comparison of $k_{\mathrm{tr} 1}, k_{\mathrm{tr} 2}$, and $k_{\mathrm{tr}}$ for different monomers

\begin{tabular}{cccc}
\hline Monomer & $k_{\text {tr1 }}\left(\mathrm{M}_{1}\right) / k_{\text {tr } 1}\left(\mathrm{M}_{2}\right)^{\mathrm{a}}$ & $k_{\mathrm{tr} 2}\left(\mathrm{M}_{1}\right) / k_{\mathrm{tr} 2}\left(\mathrm{M}_{2}\right)^{\mathrm{b}}$ & $k_{\mathrm{tr}}\left(\mathrm{M}_{1}\right) / k_{\mathrm{tr}}\left(\mathrm{M}_{2}\right)^{\mathrm{c}}$ \\
\hline MMA/St & 1.45 & 0.75 & 0.95 \\
EA/St & $13-16$ & $34-97$ & 120 \\
EA/MMA & $8.8-11$ & $43-130$ & 115 \\
\hline
\end{tabular}

${ }^{\mathrm{a}}$ Calculated from $k_{\mathrm{tr} 1}$ values in Table II. ${ }^{\mathrm{b}}$ Calculated from $k_{\mathrm{tr} 2}$ values in Table II.

${ }^{\mathrm{c}}$ Calculated from $C_{\mathrm{tr}}$ and $k_{\mathrm{p}}$ values in Table I.

ble II where the values for MA were used for EA.

If the rate determining step of AFCT of MBMA would be addition step, $k_{\text {tr } 1}>k_{\text {tr } 2}$ can be rationalized similarly with $k_{\mathrm{p} 1}>k_{\mathrm{p} 2}$. Although an excess amount of monomer relative to MBMA is preferable for incorporation of MBMA unit as a unit consisting of main chain, MBMA as effective AFCT agent cannot be incorporated in the copolymers of St, MMA, and MA under the conditions of higher monomer concentrations than MBMA ([MBMA]/[M] $<0.1) .{ }^{5}$ Furthermore, the adduct radical of MBMA cannot be detected by ESR spectroscopy. ${ }^{17}$ These findings indicate that addition to MBMA is slower than $\beta$-fragmentation of adduct radical.

The EA radical would be inherently more reactive than those of the St and MMA radicals as expected from the larger $Q$ values for St and MMA than EA. ${ }^{36}$ The EA unit smaller than the St and MMA units would result in a smaller difference between $k_{\mathrm{tr} 1}$ and $k_{\mathrm{tr} 2}$ in the magnitude as can be seen from Table II. The $k_{\text {tr1 }} / k_{\text {tr } 2}$ value decreased in the similar order with the $k_{\mathrm{p} 1} / k_{\mathrm{p} 2}$ value and the largest values for MMA were estimated. Comparison of the ratio of the rate constants in Table III reveals that the ratios for EA/St are the largest. Although the $k_{\text {tr } 1}\left(\mathrm{M}_{1}\right) / k_{\text {tr } 1}\left(\mathrm{M}_{2}\right)$ and $k_{\text {tr1 }}\left(\mathrm{M}_{1}\right) / k_{\text {tr } 1}\left(\mathrm{M}_{2}\right)$ values for the reactions with MBMA depend on the reactivities of the oligomer radicals of $M_{1}$ and $M_{2}$ at the same degrees of polymerization, the steric effect ascribed to the one or two monomer units consisting of the radical would be a decisive factor to generate a considerable difference between $k_{\mathrm{p} 1}$ and $k_{\mathrm{p} 2}\left(k_{\mathrm{p} 1}>k_{\mathrm{p} 2}\right)$.

The polar and resonance effects of the substituent on the rate constants should be considered when we compare the reactivities among the oligomer radicals of St, MMA, and EA. For example, the greater rate constants of the EA radicals would be ascribed to less significant resonance effect of the carboethoxy group in comparison with the phenyl and the methyl and carbomethoxy groups for the St and MMA radicals, respectively. However, the effects of polar and resonance effects, which were not so siginifcant as the steric effect, on the reactivities of the primary and secondary propagating radicals could not be discussed in the present study.

\section{CONCLUSIONS}

The unsaturated oligomers of St, MMA, and EA were obtained using high concentrations of AFCT agent MBMA to estimate the reactivities of the primary and secondary propagating radicals in chain transfer polymerizations. Kinetic equation for determination of the ratios of rate constants, $k_{\mathrm{tr} 1} / k_{\mathrm{p} 1}$ and $k_{\mathrm{tr} 2} / k_{\mathrm{p} 2}$, based on the relative amounts of the oligomers consisting of one and two monomer units. Although the ${ }^{1} \mathrm{H}$ NMR resonances of the products were not completely assigned, quantification of the amount of unsaturated was possible using the resonances of the protons of the unsaturated end groups arising from AFCT. The rate constant of AFCT for primary propagating radicals, secondary propagating radicals, and polymer radicals were evaluated as $k_{\mathrm{tr} 1}, k_{\mathrm{tr} 2}$, and $k_{\mathrm{tr}}$, respectively, using the rate constants for propagation of the respective radicals, $k_{\mathrm{p} 1}$, $k_{\mathrm{p} 2}$, and $k_{\mathrm{p}}$ values, in the literatures. The rate constants for AFCT for primary propagating radicals, secondary propagating radicals, and propagating radical as well as the propagation rate constants decrease in the following order: $k_{\mathrm{tr} 1}>k_{\mathrm{tr} 2}>k_{\mathrm{tr}}$. The similar reactivity 
orders for different reactions suggest that the steric effects arising from one and two monomer units primarily differentiate the reactivities in propagation and AFCT. The dimer of MBMA was found to form together with the unsaturated oligomers from the monomers because much slower propagation rate of MBMA radical suppressed extension of the MBMA sequence. Formation of the products consisting of more than three monomer units would not bias the $k_{\mathrm{tr} 1} / k_{\mathrm{p} 1}$ and $k_{\mathrm{tr} 2} / k_{\mathrm{p} 2}$ obtained in this study.

\section{REFERENCES}

1. G. F. Meijs, E. Rizzardo, and S. H. Thang, Macromolecules, 21, 3122 (1988)

2. G. F. Meijs, E. Rizzardo, and S. H. Thang, Polym. Bull., 24, 501 (1990).

3. G. F. Meijs, T. C. Morton, E. Rizzardo, and S. H. Thang, Macromolecules, 24, 3689 (1991).

4. E. Rizzardo, Y. K. Chong, R. A. Evans, G. Moad, and S. H. Thang, Macromol. Symp., 111, 1 (1996).

5. B. Yamada, S. Kobatake, and T. Otsu, Polym. J., 24, 281 (1992).

6. S. A. F. Bon, S. R. Morseley, C. Waterson, and D. F. M. Haddleton, Macromolecules, 33, 5819 (2000).

7. T. Sato, M. Seno, M. Kobayashi, T. Kohno, and H. Tanaka, Eur. Polym. J., 31, 29 (1995).

8. B. Yamada and S. Kobatake, Prog. Polym. Sci., 19, 1089 (1994).

9. D. Colombani and P. Chaumont, Prog. Polym. Sci., 21, 439 (1996).

10. B. Yamada and O. Konosu, Kobunshi Ronbunshu, 54, 723 (1997)

11. K. Tanaka and B. Yamada, Macromol. Chem. Phys., 201, 1565 (2000).

12. B. Yamada, Prepr. ACS Div. Polym. Mater. Sci. Eng., 84, 851 (2001).

13. B. Yamada, O. Konosu, K. Tanaka, and F. Oku, Polymer, 41, $5625(2000)$.

14. B. Yamada, S. Kobatake, and S. Aoki, Polym. Bull., 31, 263 (1993)
15. B. Yamada, S. Kobatake, and S. Aoki, Macromolecules, 26, 5099 (1993).

16. S. Kobatake and B. Yamada, J. Polym. Sci., Part A: Polym. Chem., 34, 95 (1996).

17. B. Yamada, unpublished result.

18. G. Moad, E. Rizzardo, D. H. Solomon, and A. L. J. Beckwith, Polym. Bull., 29, 647 (1992).

19. P. B. Zetterlund, W. K. Busfield, and I. D. Jenkins, Macromolecules, 32, 8041 (1999).

20. D. A. Shipp, T. A. Smith, D. H. Solomon, and G. Moad, Macromol. Rapid Commun., 16, 837 (1995).

21. M. Deady, A. W. H. Mau, G. Moad, and T. H. Spurling, Makromol. Chem., 194, 1691 (1993).

22. A. A. Gridnev and S. D. Ittel, Macromolecules, 29, 5864 (1996).

23. H. Friebolin, "Basic One- and Two-Dimensional NMR Spectroscopy”, VCH Publishers, Weinheim, 1993, p 54.

24. K. Hatada, T. Kitayama, K. Ute, Y. Terawaki, and T. Yanagida, Macromolecules, 30, 754 (1997).

25. P. A. Lovell, T. H. Shah, and F. Heatley, Polym. Commun., 32, 98 (1991).

26. N. M. Ahmad, F. Heatley, and P. A. Lovell, Macromolecules, 31, 2822 (1998).

27. M. Azukizawa, B. Yamada, D. J. T. Hill, and P. J. Pomery, Macromol. Chem. Phys., 201, 774 (2000).

28. B. Yamada, M. Azukizawa, H. Yamazoe, D. J. T. Hill, and P. J. Pomery, Polymer, 41, 5611 (2000).

29. B. C. Gilbert, J. R. L. Smith, E. C. Milne, A. C. Whitwood, and P. Taylor, J. Chem. Soc., Perkin Trans. 2, 1759 (1994).

30. M. E. Best and P. H. Kasai, Macromolecules, 22, 2622 (1989).

31. J. Chiefari, J. Jeffery, R. T. A. Mayadunne, G. Moad, E. Rizzardo, and S. H. Thang, Macromolecules, 32, 7700 (1999).

32. J. S. S. Toh, D. M. Huang, P. A. Lovell, and R. G. Gilbert, Polymer, 42, 1915 (2001).

33. R. G. Gilbert, Pure Appl. Chem., 68, 1491 (1996).

34. S. Beuermann, M. Buback, T. P. Davis, R. G. Gilbert, R. A. Hutchinson, O. F. Olaj, G. T. Russell, J. Schweer, and A. M. van Herk, Macromol. Chem. Phys., 198, 1545 (1997).

35. S. Beuermann, D. A. Paquet, Jr., J. H. McMinn, and R. A. Hutchinson, Macromolecules, 29, 4206 (1996).

36. G. Odian, "Principles of Polymerization", 3rd ed, John Wiley \& Sons, Inc., New York, N.Y., 1991, p 481. 